\title{
(2) OPEN ACCESS \\ Successful electroconvulsive therapy for depression in a man with cerebral amyloid angiopathy
}

\author{
Geert Schurgers (10), ${ }^{1}$ Baer M G Arts, ${ }^{1,2}$ Alida A Postma, ${ }^{2,3}$ Anna de Kort ${ }^{4,5}$
}

${ }^{1}$ Department of Psychiatry and Neuropsychology, Maastricht University Medical Centre+, Maastricht, The Netherlands ${ }^{2}$ Maastricht University School for Mental Health and Neuroscience, Maastricht, The Netherlands

${ }^{3}$ Department of Radiology and Nuclear Medicine, Maastricht University Medical Centre+, Maastricht, The Netherlands ${ }^{4}$ Department of Neurology, Radboud University Medical Center, Nijmegen, The Netherlands

${ }^{5}$ Radboud University Donders Institute for Brain Cognition and Behaviour, Nijmegen, The Netherlands

Correspondence to Geert Schurgers; geert.schurgers@mumc.nl

Accepted 13 January 2021

Check for updates

(c) BMJ Publishing Group Limited 2021. Re-use permitted under CC BY-NC. No commercial re-use. See rights and permissions. Published by BMJ.

\footnotetext{
To cite: Schurgers $G$, Arts BMG, Postma AA et al. BMJ Case Rep

2021;14:e238922.

doi:10.1136/bcr-2020-

238922
}

\section{SUMMARY}

Cerebral amyloid angiopathy (CAA) is a condition characterised by accumulation of amyloid beta protein $(A B)$ in the wall of cerebral blood vessels which increases the risk of intracranial haemorrhage and contributes to cognitive impairment. We describe the case of a man around the age of 70 with 'probable' CAA according to the modified Boston criteria and severe depression whose depression was treated successfully with electroconvulsive therapy (ECT). To the best of our knowledge, there are no earlier published reports of ECT in a patient with CAA. We briefly discuss possible safety measures for these patients, the impact of ECT on cognition in CAA and a possible influence of $E C T$ on $A \beta$ clearance.

\section{BACKGROUND}

Cerebral amyloid angiopathy (CAA) is characterised by accumulation of amyloid beta protein $(\mathrm{A} \beta)$ in the wall of cerebral blood vessels, mainly cortical and leptomeningeal arterioles. ${ }^{1}$ It increases the risk of spontaneous intracranial haemorrhage and contributes to cognitive impairment. ${ }^{23}$ Possible psychiatric manifestations include personality changes, behavioural disturbances and/or depression. ${ }^{4}$ Diagnosis depends on the modified Boston criteria using pathologic, radiographic and/or clinical information. ${ }^{5}$ CAA is common: clinicopathological studies show a prevalence of $55 \%-59 \%$ in the demented and $28 \%-39 \%$ in the non-demented elderly population. ${ }^{6}$

Here, we describe the case of an elderly man with a history of intracranial haemorrhage with underlying 'probable' CAA according to the modified Boston criteria who underwent a successful course of electroconvulsive therapy (ECT). To the best of our knowledge, there are no earlier published reports of ECT in a patient with CAA. ECT is one of the most effective procedures for the treatment of depression with no absolute contraindications. Extra caution seems warranted in patients with a history of intracranial haemorrhage since ECT causes transient haemodynamic changes such as increased heart rate and blood pressure. ${ }^{8}$ However, successful ECT has been reported in a patient with recent subarachnoid haemorrhage ${ }^{9}$ or in the presence of subdural haemorrhage. ${ }^{10}$

This case is an example of a fundamental part of modern ECT practice: weighing potential benefits against risks and side-effects. After presenting the case, we discuss possible safety measures for patients with CAA, the impact of ECT on cognition in CAA and a possible influence of ECT on $A \beta$ clearance.

\section{CASE PRESENTATION}

Our patient was a man around the age of 70 who was hospitalised due to spontaneous cerebral haemorrhage 12 months before admission to our psychiatric ward. MRI of the brain at the time of the cerebral haemorrhage revealed subarachnoid haemorrhage in the right central and precentral sulcus and a small focus of intraparenchymal bleeding in the left parietal lobe. The MRI scan also showed multiple microbleeds and superficial siderosis, both compatible with 'probable' CAA. ${ }^{5}$ Clinical signs of the stroke were minor disturbances of fine motor skills of the left hand but the patient recovered fully within weeks.

In the following months, the patient developed pain and loss of strength in his left leg. After extensive investigation, these problems were deemed functional. Six weeks prior to his hospitalisation at our ward, the patient's physiotherapist told him no further improvement regarding his leg was to be expected. Since then the patient started to develop depressive symptoms for the first time in his life such as low mood, loss of interest in his surroundings, disrupted sleep, excessive worries and restlessness. Delusional thoughts (such as the false idea that he was going to lose his house) and catatonic signs (such as mutism, staring and perseveration) appeared in the following weeks. Ultimately, the patient was hospitalised at the psychiatric ward of our general university hospital after a primary care physician referred him to the emergency department. Psychotic depression with catatonia was the preliminary diagnosis. Together with the aforementioned symptoms, the patient showed remarkable cognitive dysfunction such as disorientation, impaired memory and apraxia. The patient's wife stated that her husband showed no signs of cognitive dysfunction up until the moment he started developing depressive symptoms.

\section{INVESTIGATIONS}

Routine blood testing and urinalysis showed no abnormalities. On admission to the psychiatric ward, brain MRI was repeated which showed similar results compared with the MRI scan 12 months earlier with no new cerebrovascular lesions (see figure 1). Cerebrospinal fluid (CSF) analysis revealed decreased levels of $A \beta_{40}$ and $A \beta_{42}(2632$ (ref. >3200) and 385 (ref. >500) ng/L, respectively) with normal tau and phospho-tau levels (340 (ref. <350) and 48 (ref. <85) ng/L, respectively). The CSF sample showed no signs of inflammation of the central nervous system such as elevated leucocyte count or protein levels. When assessing 

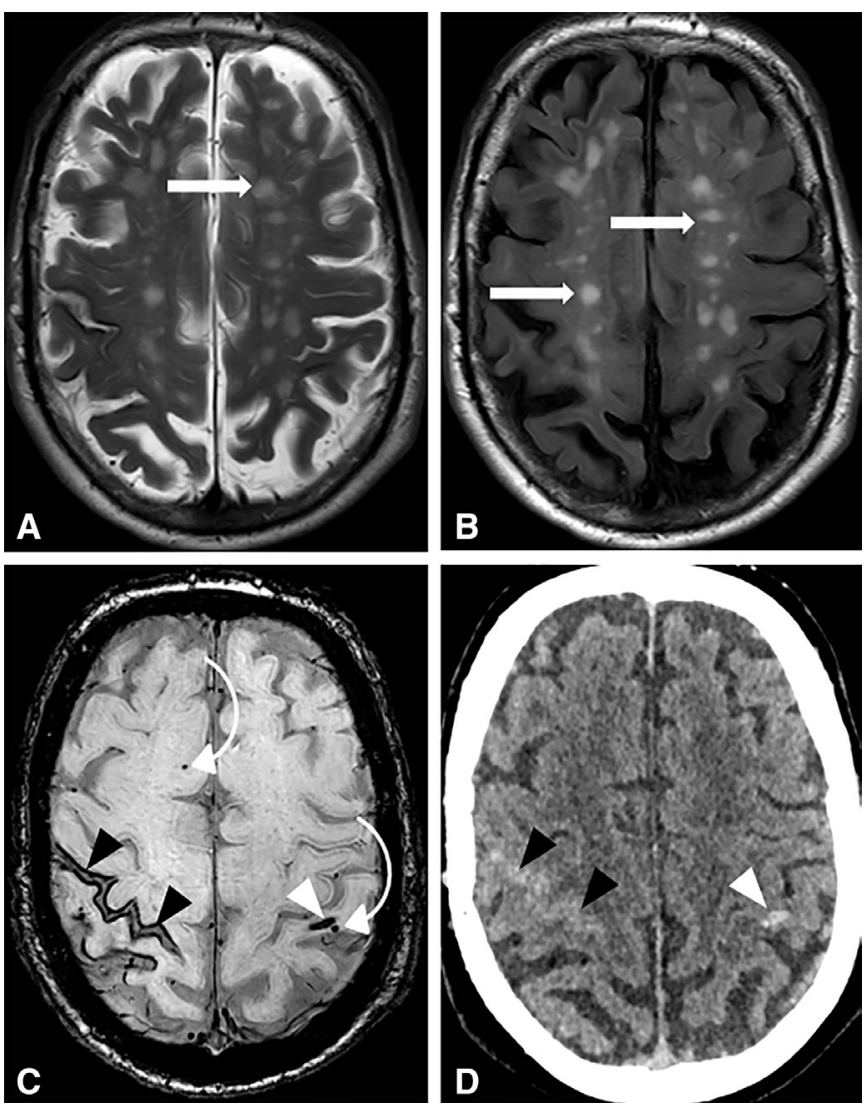

Figure $1 \mathrm{MRI}(\mathrm{A}, \mathrm{B}, \mathrm{C})$ and $C T(\mathrm{D})$ images of the brain made prior to electroconvulsive therapy. White matter hyperintensities (straight white arrows) classified as Fazekas grade 2 are seen at T2-weighted (A) and fluid-attenuated inversion recovery images (B). Subarachnoid haemorrhage (black arrowheads) in the right parietal region is seen at susceptibility weighted imaging (SWI) (C) and CT (D) with superficial siderosis in this region at SWI (C). Intraparenchymal haemorrhage (white arrowhead) in the left parietal gyrus is seen at SWI (C) and CT (D). Microbleeds (bended arrows) are seen at SWI (C).

the patient's cognitive functions, he attained a score of 25/30 on the Mini Mental State Examination (MMSE). More extensive neuropsychological examination objectified deficits in mental processing speed, attention, executive functions, memory and visuoconstruction (see table 1).

\section{DIFFERENTIAL DIAGNOSIS}

Systemic causes of mood dysregulation such as anaemia and hypothyroidism were ruled out through blood testing. The (sub) acute time course of the cognitive deterioration and normal tau levels in the CSF made an advanced neurodegenerative condition such as Alzheimer's disease (AD) unlikely. Although AD and CAA are overlapping conditions, ${ }^{11}$ the fact that not only $\mathrm{A} \beta_{42}$ but also $\mathrm{A} \beta_{40}$ levels in the CSF were decreased pointed to CAA rather than AD. ${ }^{12} 13$ Delirium was considered unlikely since apart from disorientation typical symptoms of delirium such as altered or fluctuating consciousness were absent. Also, typical causes of delirium such as infection or electrolyte disturbances were ruled out. Brain MRI excluded an acute cerebrovascular cause of the rapid cognitive decline. Psychotic depression was thus considered the main diagnosis and the patient was treated accordingly.

\section{TREATMENT}

Prior to hospitalisation, our patient was treated with sertraline up to $100 \mathrm{mg}$ daily on an outpatient basis for several weeks with no success. Once he was hospitalised, lorazepam (1 mg three times a day) was initiated which led to the disappearance of the catatonic symptoms. Nortriptyline was started (50 mg once daily resulting in a therapeutic blood level of $134 \mu \mathrm{g} / \mathrm{L})$ together with haloperidol ( $0.5 \mathrm{mg}$ once daily) to treat the depressive symptoms and nihilistic delusions.

Despite psychopharmacological treatment for several weeks, the patient's condition worsened. Eventually, a course of ECT was initiated. Evidence-based guidelines or case reports of ECT in patients with CAA were lacking. A neurologist specialised in neurovascular disease advised to avoid severe elevations in blood pressure during the procedure. To achieve this, the beta blocker esmolol $(50 \mathrm{mg}$ before the seizure, $50 \mathrm{mg}$ once again after the seizure if needed) and the opioid agonist alfentanil (0.25- $0.5 \mathrm{mg}$ before the seizure) were administered intravenously to this $89 \mathrm{~kg}$ weighing man together with the usual anaesthetic (etomidate $20 \mathrm{mg}$ ) and muscle relaxant (succinylcholine $100 \mathrm{mg}$ ). Using this medication combination, the ictal and postictal systolic blood pressure did not exceed $160 \mathrm{~mm}$ $\mathrm{Hg}$ and the diastolic blood pressure stayed well below $100 \mathrm{~mm}$ $\mathrm{Hg}$; these values were comparable to blood pressure measurements on non-ECT days. The patient underwent bitemporal ECT treatments twice weekly for a total of six ECT sessions (seizure duration 35-67s on electroencephalogram) with the use of a Thymatron System IV device (Somatics, LLC, Lake Bluff, Illinois, USA). The following device parameters were used: pulse width $=0.5 \mathrm{~ms}$, frequency $=50-70 \mathrm{~Hz}$, stimulus duration $=6.8-7.8 \mathrm{~s}$ and total charge $=352-555 \mathrm{mC}$.

\section{OUTCOME AND FOLLOW-UP}

The ECT course was successful. Already after the first treatment, a clear improvement was seen as psychomotor retardation decreased significantly and the patient appeared remarkably more communicative. By the fourth treatment, the patient reported a dramatic improvement in his mood. ECT was stopped after the sixth treatment because remission was achieved. The total score on the clinician-rated Inventory of Depressive Symptomatology decreased from 25 pre-ECT (indicating moderate depression, probably an underestimation due to difficulties performing a complete assessment of symptoms due to the severe mood and cognitive disturbance) to seven post-ECT (indicating remission of depressive symptomatology). The subscore for anxiety on the Hospital Anxiety and Depression Scale decreased from 13/21 to $1 / 21$, for depression from $13 / 21$ to $4 / 21$.

To assess whether the ECT was inflicting additional cerebral lesions, brain MRI was repeated after the fourth ECT treatment. No changes in the extent of superficial hemosiderosis or white matter hyperintensities and the number of microbleeds were observed nor new lesions or oedema. We did not observe any complications during the ECT course although cognitive problems persisted. The MMSE scores dropped from 25/30 pre-ECT to $24 / 30$ during the ECT course. Three weeks post-ECT, a neuropsychological re-evaluation took place. The patient's MMSE score now was 29/30 and improvements in working speed, attention and executive functions were seen, most likely due to resolution of depressive symptomatology. In contrast, impairments in memory and visuoconstructional abilities persisted (see table 1). The remaining cognitive impairment was attributed to the cognitive side-effects of ECT and pre-existing cerebrovascular damage. Cognition improved in the months after ECT and 
Table 1 Overview of specific neuropsychological tests performed prior to ECT and 3 weeks after completion of the ECT course

\begin{tabular}{|c|c|c|c|}
\hline Name of test & Cognitive functions assessed & Performance pre-ECT & Performance post-ECT \\
\hline CST & $\begin{array}{l}\text { CST A: attention, processing speed } \\
\text { CST B: attention, processing speed } \\
\text { CST C: mental flexibility } \\
\text { CST interference score: mental flexibility }\end{array}$ & $\begin{array}{l}\text { CST A: extremely low } \\
(Z=-4.32) \\
\text { CST B: low average } \\
(Z=-1.45) \\
\text { CST C: extremely low } \\
(Z=-3.32) \\
\text { CST interference score: extremely } \\
\text { low } \\
(Z=-2.81)\end{array}$ & $\begin{array}{l}\text { CST A: low average } \\
(Z=-0.94) \\
\text { CST B: superior } \\
(Z=1.31) \\
\text { CST C: extremely low } \\
(Z=-4.81) \\
\text { CST interference score: extremely low } \\
(Z=-6.84)\end{array}$ \\
\hline SCWT & $\begin{array}{l}\text { SCWT 1: attention, processing speed } \\
\text { SCWT 2: attention, processing speed } \\
\text { SCWT 3: selective attention, ability to } \\
\text { inhibit cognitive interference } \\
\text { SCWT interference score: inhibition }\end{array}$ & $\begin{array}{l}\text { SCWT 1: extremely low } \\
(Z=-2.08) \\
\text { SCWT 2: low average } \\
(Z=-1.30) \\
\text { SCWT 3: average } \\
(Z=-0.51) \\
\text { SCWT interference score: average } \\
(Z=0.1)\end{array}$ & $\begin{array}{l}\text { SCWT 1: average } \\
(Z=-0.05) \\
\text { SCWT 2: low average } \\
(Z=-1.09) \\
\quad \text { SCWT 3: average } \\
(Z=-0.42) \\
\quad \text { SCWT interference score: average } \\
(Z=-0.31)\end{array}$ \\
\hline LDST & Processing speed, writing, reading & $\begin{array}{l}\text { Writing: extremely low }(\mathrm{Z}=-3.9) \\
\text { Reading: extremely low }(\mathrm{Z}=-2.56)\end{array}$ & $\begin{array}{l}\text { Writing: borderline/low }(\mathrm{Z}=-1.77) \\
\text { Reading: low average }(\mathrm{Z}=-1.19)\end{array}$ \\
\hline BADS & Executive functions & Total score 3 (impaired) & Total score 11 (borderline) \\
\hline 15-Words Test & $\begin{array}{l}\text { Memory: immediate recall, delayed recall, } \\
\text { recognition }\end{array}$ & $\begin{array}{l}\text { Immediate: borderline }(\mathrm{Z}=-1.61) \\
\text { Delayed: extremely low }(\mathrm{Z}=-2.94) \\
\text { Recognition: borderline }(\mathrm{Z}=-1.61)\end{array}$ & $\begin{array}{l}\text { Immediate: extremely low }(\mathrm{Z}=-2.38) \\
\text { Delayed: extremely low }(\mathrm{Z}=-2.14) \\
\text { Recognition: borderline }(\mathrm{Z}=-1.95)\end{array}$ \\
\hline VAT & Memory: learning visual associations & Percentile 1 (extremely low) & Percentile 1 (extremely low) \\
\hline $\begin{array}{l}\text { Visuoconstruction tests (drawing of meander } \\
\text { pattern, cubes, honeycomb, clock) }\end{array}$ & Visuoconstruction & $\begin{array}{l}\text { Clock drawing 'poor', rest 'wrong' } \\
\text { (rating: good-poor-wrong) }\end{array}$ & $\begin{array}{l}\text { Cube drawing 'poor', rest 'wrong' } \\
\text { (rating: good-poor-wrong) }\end{array}$ \\
\hline BNT & Naming & $\begin{array}{l}\text { Score 13/15 } \\
\text { (above cut-off, which is 12.5) }\end{array}$ & $\begin{array}{l}\text { Score } 14 / 15 \\
\text { (above cut-off, which is } 12.5 \text { ) }\end{array}$ \\
\hline
\end{tabular}

Z-scores $<2.00$ indicate impairment.

BADS, Behavioural Assessment of the Dysexecutive Syndrome; BNT, Boston Naming Test; CST, concept shifting task; ECT, electroconvulsive therapy; LDST, Letter Digit Substitution Test; SCWT, Stroop Colour and Word Test; VAT, Visual Association Test.

remained stable thereafter, according to the patient's wife. In the year after ECT, there were no signs of depression relapse.

\section{DISCUSSION}

To the best of our knowledge, this is the first case report of successful ECT in a patient with 'probable' CAA. Given the high prevalence of CAA in the elderly and the fact that ECT is a preferred treatment method in severe late-life depression, ${ }^{14}$ it is likely that many patients with unrecognised CAA are treated with ECT, without specific safety measures. Considering the low rates of serious ECT-related adverse events in large patient populations, ${ }^{15-17}$ one could argue that the risk of provoking intracerebral haemorrhage is probably low. However, Weisberg et al reported a case of intracerebral haemorrhage following ECT in which CAA was considered a possible underlying cause. ${ }^{18}$ It is unclear whether or not specific safety measures (such as neuroimaging prior to/during ECT or interventions to reduce periprocedural blood pressure) provide safety benefits in patients with probable CAA. Evidence-based guidelines on this matter are lacking. Esmolol seems to be a good candidate to reduce blood pressure and heart rate after electrical stimulation but shortening of the seizure duration could possibly impede ECT efficacy. ${ }^{19}$ Adjuvant remifentanil has proven to reduce systolic blood pressure during ECT and may lengthen seizure duration if it allows for a dose reduction of the main anaesthetic. ${ }^{20}$

In line with the available literature, our case suggests that pre-existing cognitive impairment or the presence of age-related brain changes should not withhold psychiatrists to treat elderly patients with severe mood disorders with ECT. Since CAA is frequently associated with cognitive impairment and cognitive side-effects after ECT are common, one could be worried about a negative impact of ECT on cognition in patients with CAA. However, when assessing our patient 3 weeks after the last ECT treatment, his MMSE score and performance in a broader neuropsychological examination improved. In line with this, Obbels et al recently reported an increase in MMSE scores during ECT treatment in a sample of patients with late-life depression, specifically in a subset of patients with a low $(<24)$ baseline MMSE score. ${ }^{21}$ In addition, in a recent study, Bouckaert et al did not find any association between age-related brain changes (such as hippocampal atrophy, white matter hyperintensities and total amyloid load) and ECT outcome. ${ }^{22}$ According to the authors, 'ECT should be considered in subjects with late life depression irrespective of accumulating age-related brain pathology'.

Arguably, ECT could have therapeutic effects in CAA beyond the treatment of depression. It is hypothesised that the cerebral A $\beta$ accumulation in CAA, as in $\mathrm{AD}$, is not the result of excessive $\mathrm{A} \beta$ production but rather of diminished clearance from the brain. ${ }^{11}$ Zimmerman et al demonstrated a small, but significant, transient increase in four $A \beta$ isoforms $(1-42,1-40, x-42, x-40)$ in the plasma of depressed individuals $30 \mathrm{~min}$ after ECT. ${ }^{23}$ Kranaster et al found an increase in $\mathrm{A} \beta_{1-42}$ in the CSF of ECT-responders which was positively correlated to the number of ECT sessions. ${ }^{24}$ It is tempting to speculate that such an $A \beta$ increase in plasma or CSF reflects increased $A \beta$ clearance from the brain, perhaps due to ECT-induced transient opening of the blood-brain barrier. ${ }^{25}$ In another paper on the impact of ECT on A $\beta$, Vandenbulcke et al reported the asymmetrical $\mathrm{A} \beta$ distribution in a patient 
with AD 20 months after unilateral ECT, possibly due to ECTinduced alterations in $\mathrm{A} \beta$ deposition. ${ }^{26}$ Altered $\mathrm{A} \beta$ deposition might be a consequence of glial cell activation by ECT. ${ }^{27}$ Clearly, further research in this area is needed before firm conclusions can be drawn. Unfortunately, we did not have the possibility to re-examine the CSF of our patient so we cannot make statements on the impact of ECT on $\mathrm{A} \beta$ in this specific case.

\section{Learning points}

- This is the first case report of electroconvulsive therapy (ECT) in a patient with depression and cerebral amyloid angiopathy (CAA), a common condition among elderly characterised by accumulation of amyloid beta protein $(A \beta)$ in the wall of cerebral blood vessels leading to intracranial haemorrhage and cognitive impairment.

- Following a vascular neurologist's advice, we used a beta blocker and opioid antagonist to limit blood pressure during ECT and reduce the risk of cerebral haemorrhage. We performed brain MRI after four ECT treatments to assess whether ECT was inflicting additional cerebral lesions, which was not the case. Evidence-based guidelines on such safety measures for patients with CAA are non-existent.

- Our case suggests ECT should be considered in elderly patients with severe mood disorders even in the presence of CAA.

- Preliminary evidence suggests that ECT stimulates $A \beta$ elimination from the brain but further research is needed before firm conclusions can be drawn.

Acknowledgements Dr Marcel M. Verbeek and Professor Pascal Sienaert, renowned experts in the fields of CAA and ECT, respectively, provided additional advice and assisted in selecting an appropriate journal for publication of the manuscript. Dr Claire Wolfs assisted in interpreting and summarising the neuropsychological findings.

Contributors GS was directly involved in the treatment of the patient described in the article, took the initiative to write this case report and was the main author of the manuscript. BMGA was the supervising psychiatrist involved in the treatment of the patient and critically revised multiple versions of the manuscript. AAP critically revised multiple versions of the manuscript, especially the parts on neuroradiological aspects, and provided the images. AdK critically revised multiple versions of the manuscript, especially the parts on clinical and pathophysiological aspects of cerebral amyloid angiopathy.

Funding The authors have not declared a specific grant for this research from any funding agency in the public, commercial or not-for-profit sectors.

Competing interests AAP reports an institutional grant from Siemens Healthcare, outside the submitted work.

\section{Patient consent for publication Obtained.}

Provenance and peer review Not commissioned; externally peer reviewed.

Open access This is an open access article distributed in accordance with the Creative Commons Attribution Non Commercial (CC BY-NC 4.0) license, which permits others to distribute, remix, adapt, build upon this work non-commercially, and license their derivative works on different terms, provided the original work is properly cited and the use is non-commercial. See: http://creativecommons.org/ licenses/by-nc/4.0/.

ORCID iD

Geert Schurgers http://orcid.org/0000-0003-4343-5242

\section{REFERENCES}

1 Attems J, Jellinger K, Thal DR, et al. Review: sporadic cerebral amyloid angiopathy. Neuropathol App/ Neurobiol 2011;37:75-93.

2 Charidimou A, Gang Q, Werring DJ. Sporadic cerebral amyloid angiopathy revisited: recent insights into pathophysiology and clinical spectrum. J Neurol Neurosurg Psychiatry 2012;83:124-37.

3 Banerjee G, Carare R, Cordonnier C, et al. The increasing impact of cerebral amyloid angiopathy: essential new insights for clinical practice. J Neurol Neurosurg Psychiatry 2017;88:982-94.

4 Gahr M, Nowak DA, Connemann BJ, et al. Cerebral amyloidal angiopathy - A disease with implications for neurology and psychiatry. Brain Res 2013;1519:19-30.

5 Linn J, Halpin A, Demaerel P, et al. Prevalence of superficial siderosis in patients with cerebral amyloid angiopathy. Neurology 2010;74:1346-50.

6 Keage HAD, Carare RO, Friedland RP, et al. Population studies of sporadic cerebral amyloid angiopathy and dementia: a systematic review. BMC Neurol 2009;9:3.

7 Sienaert P. What we have learned about electroconvulsive therapy and its relevance for the practising psychiatrist. Can J Psychiatry 2011;56:5-12.

8 Van Herck E, Sienaert P, Hagon A. Elektroconvulsietherapie bij patiënten met intracraniële aneurysmata: gevalsbespreking en overzicht van de literatuur. Tijdschr Psychiatr 2009;51:43-51.

9 Doddi SR, Lotz M, Regenold WT, et al. Electroconvulsive therapy in a patient with a recent subarachnoid hemorrhage. J Ect 2018;34:e2-4.

10 Wijeratne C, Shome S. Electroconvulsive therapy and subdural hemorrhage. J Ect 1999;15:1-9.

11 Greenberg SM, Bacskai BJ, Hernandez-Guillamon M, et al. Cerebral amyloid angiopathy and Alzheimer disease - one peptide, two pathways. Nat Rev Neurol 2020;16:30-42.

12 Ritchie C, Smailagic N, Noel-Storr AH, et al. CSF tau and the CSF tau/ABeta ratio for the diagnosis of Alzheimer's disease dementia and other dementias in people with mild cognitive impairment (MCI). Cochrane Database Syst Rev 2017;3:CD010803.

13 Charidimou A, Friedrich JO, Greenberg SM, et al. Core cerebrospinal fluid biomarker profile in cerebral amyloid angiopathy: a meta-analysis. Neurology 2018;90:e754-62.

14 Geduldig ET, Kellner CH. Electroconvulsive therapy in the elderly: new findings in geriatric depression. Curr Psychiatry Rep 2016;18:40.

15 Blumberger DM, Seitz DP, Herrmann N, et al. Low medical morbidity and mortality after acute courses of electroconvulsive therapy in a population-based sample. Acta Psychiatr Scand 2017;136:583-93.

16 Nuttall GA, Bowersox MR, Douglass SB, et al. Morbidity and mortality in the use of electroconvulsive therapy. J Ect 2004;20:237-41.

17 Watts BV, Groft A, Bagian JP, et al. An examination of mortality and other adverse events related to electroconvulsive therapy using a national adverse event report system. J Ect 2011;27:105-8.

18 Weisberg LA, Elliott D, Mielke D. Intracerebral hemorrhage following electroconvulsive therapy. Neurology 1991;41:1849.

19 Boere E, Birkenhäger TK, Groenland THN, et al. Beta-blocking agents during electroconvulsive therapy: a review. Br J Anaesth 2014;113:43-51.

20 Takekita Y, Suwa T, Sunada N, et al. Remifentanil in electroconvulsive therapy: a systematic review and meta-analysis of randomized controlled trials. Eur Arch Psychiatry Clin Neurosci 2016;266:703-17.

21 Obbels J, Vansteelandt K, Verwijk E, et al. MMSE changes during and after ECT in late-life Depression: a prospective study. Am J Geriatr Psychiatry 2019;27:934-44.

22 Bouckaert F, Emsell L, Vansteelandt K, et al. Electroconvulsive therapy response in late-life depression unaffected by age-related brain changes. J Affect Disord 2019;251:114-20.

23 Zimmermann R, Schmitt $\mathrm{H}$, Rotter $\mathrm{A}$, et al. Transient increase of plasma concentrations of amyloid $\beta$ peptides after electroconvulsive therapy. Brain Stimul 2012;5:25-9.

24 Kranaster L, Aksay SS, Bumb JM, et al. Electroconvulsive therapy selectively enhances amyloid $\beta$ 1-42 in the cerebrospinal fluid of patients with major depression: a prospective pilot study. Eur Neuropsychopharmacol 2016;26:1877-84.

25 Andrade C, Bolwig TG, therapy E. Electroconvulsive therapy, hypertensive surge blood-brain barrier breach, and amnesia: exploring the evidence for a connection. $J$ Ect 2014;30:160-4.

26 Vandenbulcke M, Bouckaert F, De Winter F-L, et al. Asymmetric amyloid deposition in the brain following unilateral electroconvulsive therapy. Biol Psychiatry 2017;81:e11-13.

27 Jansson L, Wennström M, Johanson A, et al. Glial cell activation in response to electroconvulsive seizures. Prog Neuropsychopharmacol Biol Psychiatry 2009;33:1119-28. 
Copyright 2021 BMJ Publishing Group. All rights reserved. For permission to reuse any of this content visit https://www.bmj.com/company/products-services/rights-and-licensing/permissions/

BMJ Case Report Fellows may re-use this article for personal use and teaching without any further permission.

Become a Fellow of BMJ Case Reports today and you can:

- Submit as many cases as you like

Enjoy fast sympathetic peer review and rapid publication of accepted articles

Access all the published articles

Re-use any of the published material for personal use and teaching without further permission

Customer Service

If you have any further queries about your subscription, please contact our customer services team on +44 (0) 2071111105 or via email at support@bmj.com.

Visit casereports.bmj.com for more articles like this and to become a Fellow 